\section{Ramificação e distribuição dos nervos frênicos no diafragma de jumentos do Nordeste brasileiro (Asinus asinus)}

\section{Branching and distribution of the phrenic nerves in the diaphragm of Brazilian Northeast asses (Asinus asinus)}

\author{
Adelmar Afonso de AMORIM JÚNIOR ${ }^{1}$; Irvênia Luiza de Santis PRADA ${ }^{2}$; \\ Maria Angélica MIGLINO²
}

CORRESPONDENCE TO:

Maria Angélica Miglino

Departamento de Cirurgia

Faculdade de Medicina Veterinária e Zootecnia da USP

Av. Prof. Dr. Orlando Marques de

Paiva, 87 - Cidade Universitária

Armando do Salles Oliveira

05508-900 - São Paulo - SP - Brasil

e-mail: miglino@usp.br

1 - Faculdade de Medicina Universidade Federal de

Pernambuco

Recife - PE

2 - Faculdade de Medicina

Veterinária e Zootecnia da

$U S P$ - $S P$

\title{
RESUMO
}

Mediante fixação e dissecação, foram examinadas, em 30 diafragmas de jumentos do Nordeste brasileiro (Asinus asinus), sendo 15 de machos e 15 de fêmeas, adultos, a ramificação e a distribuição dos nervos frênicos direito e esquerdo, tendo-se observado que:

1) Os nervos frênicos resolvem-se mais freqüentemente em tronco lombocostal e ramo esternal, tanto à direita $(76,7 \%)$ como à esquerda $(53,3 \%)$, com disposição simétrica em parte dos casos $(43,3 \%)$;

2) Os ramos lombares destinam-se aos pilares correspondentes (pars lumbalis), cedendo ainda, da direita, filete nervoso ao pilar medial esquerdo $(3,3 \%)$, folíolo dorsal direito $(6,7 \%)$ e folíolo ventral $(3,3 \%)$ e, o da esquerda, filete nervoso ao pilar medial direito $(53,3 \%)$, folíolo dorsal esquerdo $(13,3 \%)$ ou folíolo ventral $(6,7 \%)$;

3) Os ramos costais distribuem-se à região dorsal da pars costalis do lado correspondente, tanto à direita como à esquerda e, ainda, à região ventral $(3,3 \%)$ à direita, ao folíolo dorsal direito $(3,3 \%)$ e, à esquerda, ao folíolo dorsal esquerdo $(10,0 \%)$;

4) Os ramos esternais distribuem-se, do mesmo lado, à pars sternalis e região ventral da pars costalis, emitindo, ainda à direita, filete nervoso para a veia cava caudal $(3,3 \%)$ ou para o folíolo ventral $(3,3 \%)$.

UNITERMOS: Diafragma; Nervo frênico; Jumentos; Anatomia.

\section{INTRODUÇÃO E LITERATURA}

$\mathrm{S}$ ão clássicos e básicos os trabalhos de Bertelli ${ }^{2,3}$ (1984, e 1985) a respeito da morfologia do diafragma em carnívoros e outros mamíferos. Com relação a determinados aspectos do comportamento dos nervos frênicos, eles vêm despertando grande atenção por parte dos pesquisadores, aspectos esses que foram particularizados, a seguir, em pesquisas também importantes, voltadas para o homem (Cavalicé, 1898) e para mamíferos (Funaoka ${ }^{2}$, 1930; Bertelli', 1933; Lutnick ${ }^{1819}, 1950,1953$ Conde $^{89}, 1957$; Neves $\left.{ }^{20}, 1968\right)$.

Nos tratados gerais de Anatomia Veterinária, alguns autores, como é o caso de Bossi er al. ${ }^{4}$ (s.d.); Lesbre $^{17}$ (1923); Ellenberger; Baum ${ }^{\prime \prime}$ (1932); Bruni; Zimmerl' (1947); Sisson; Grosmann $^{26}$ (1948) e Gonzalez y Garcia; Gonzalez Alvarez ${ }^{14}$ (1949), comentam apenas que os nervos frênicos chegam ao centro frênico e se distribuem à porção carnosa. Ainda Chaveau et al. (1905) e Lesbre ${ }^{77}$ (1923) mencionam a presença de pequenos filetes endereçados aos pilares, afirmativa esta que se aproxima da referida por Zimmerl ${ }^{27}$
(1930), segundo a qual um ou mais filetes são destinados exclusivamente aos pilares. Schwarze; Schröder ${ }^{25}$ (1972) e Getty $^{13}$ (1975) citam que os referidos nervos emitem vários ramos ao músculo, os quais inervam correspondentes do mesmo. Dobberstein; Hoffmann ${ }^{10}$ (1964) e Getty ${ }^{13}$ (1975) descrevem que estes nervos ramificam-se no diafragma, constituindo sua inervaçāo motora.

Na literatura consultada, visando apenas o grupo dos eqüídeos, esses estudos já foram concluídos relativamente a eqüinos da raça Puro Sangue Inglês (Santiago; Pereiral ${ }^{22}$, 1983) e Sem Raça Definida (Santiago ${ }^{23}$, 1986), portanto não encontrando dados suficientes, quanto ao tema, em outros representantes desse grupo de cqüídeos, como é o caso já dos asininos. Dos jumentos brasileiros, são consagrados três tipos, isto é, o jumento Paulista, o jumento da raça Pêga e o jumento Nordestino, cada um deles exibindo constituição morfológica própria, este último, com dimensōes menores que a dos outros dois. Sabemos, de outra parte, que a determinado tipo constitucional morfológico corresponde aspecto anatômico próprio.

Nesta oportunidade, propomo-nos a estudar a ramificação e 
AMORIM JÚNIOR, A.A.; PRADA. I.L.S.; MIGLINO, M.A. Ramificação e distribuição dos nervos frênicos no diafragmá de jumentos do Nordeste brasileiro. Braz. J. vet. Res. anim. Sci. Sĩo Paulo, v.33, supl., p.261-269, 1996

a distribuição dos nervos frênicos no diafragma de jumentos do Nordeste brasileiro, objetivando conhecer seu comportamento nesses animais, bem como obter dados que permitam o estabelecimento de análises comparativas dentro da referida linha de pesquisa.

No tocante à literatura especializada, atinente a esse assunto, temos o trabalho de Pancrazi ${ }^{21}$ (1926), que cuida da disposição dos nervos frênicos e suas divisões no cavalo e em outras espécies (boi, cobaia, coelho, cão e gato). O autor afirma genericamente que os principais ramos terminais são em número de três, denominando-os ramo dorsal, lateral e ventral, e este inerva a região dorsal esternal e parte da região costal, enquanto o lateral destina-se à porçāo restante da região costal, c o ramo dorsal, à regiāo lombar. Cita ainda que alguns filetes originados do ramo dorsal esquerdo atingem o pilar direito do órgão, e esclarece que a divisāo dos aludidos nervos varia segundo a espécie e entre representantes da mesma espécie. Temos também o de Santiago; Pereira ${ }^{22}$ (1983), que, estudando a inervação do diafragma de 30 eqüinos da raça Puro Sangue Inglês, 15 machos e 15 fêmeas, adultos, chegam às seguintes conclusões: 1) Os nervos frênicos terminam em ramo ventral e tronco dorsolateral à direita $(96,7 \%)$ e à esquerda $(26,7 \%)$, ou em ramo dorsal e tronco ventrolateral à esquerda $(66,7 \%)$ e à direita (3,3\%), encontrando-se ainda trifurcação à esquerda $(6,6 \%)$; os nervos frênicos direito e esquerdo comportam-se simetricamente em ramo ventral e tronco dorsolateral $(26,7 \%)$ e em ramo dorsal e tronco ventrolateral $(3,3 \%) ; 2$ ) Os ramos dorsais dos nervos frênicos inervam à esquerda $(86,6 \%)$ e à direita $(83,3 \%)$ a parte lombar do mesmo lado; fornecem filetes ao centro tendíneo do diafragma, tanto à direita como à esquerda $(6,6 \%)$; emitem filetes ao folíolo dorsal à direita $(6,6 \%) \mathrm{e}, \mathrm{cm}$ apenas uma oportunidade, enviam ramos à porçāo lombar dircita $(3,3 \%)$; 3) Quanto aos ramos laterais dos nervos frênicos, inervam à esquerda $(90,0 \%)$ e à direita $(56,6 \%)$ a parte costal, mais precisamente as porções dorsal e lateral; emitem filetes à porçāo lombar direita $(23,3 \%)$, ao folíolo dorsal direito $(20,0 \%)$ e ao esquerdo $(3,3 \%)$ e à parte costal esquerda da porção ventral $(6,6 \%)$; 4) Já os ramos ventrais dos nervos frênicos inervam à esquerda $(86,6 \%)$ e à direita $(76,6 \%)$ a porção ventral da parte costal e a parte esternal do mesmo lado; enviam ramos ao folíolo ventral $(6,6 \%)$; inervam somente a porçāo ventral da parte costal à direita $(3,3 \%)$; emitem ramos ao folíolo dorsal direito $(3,3 \%)$; enviam filetes à parede da veia caudal à direita $(3,3 \%)$; 5) Conexões "Anastomoses" homolaterais foram vistas à direita $(40 \%)$ e à esquerda $(3,3 \%)$.

Ainda, Santiago ${ }^{23}$ (1986), estudando a ramificação e distribuição dos nervos frênicos em 50 diafragmas de eqüinos Sem Raça Definida, 25 machos e 25 fêmeas, jovens e adultos, chega às seguintes conclusōes: 1) Os nervos frênicos fornecem o ramo ventral e o tronco laterodorsal $(84,0 \%)$ à direita e à esquerda $(10,0 \%)$, o ramo dorsal e o tronco lateroventral à esquerda $(80,0 \%)$ e à direita $(4,0 \%)$, encontrando-se ainda origem simultânea dos ramos dorsal, lateral e ventral à esquerda $(10,0 \%)$ e à direita $(12,0 \%)$; os nervos frênicos comportam-se simetricamente $(18,0 \%)$ quando fornecem tronco laterodorsal e ramo ventral $(10,0 \%)$ e quando fornecem ramo dorsal e tronco lateroventral e trifurcação $(4,0 \%) ; 2) \mathrm{Em}$ todas as preparações os ramos dorsais, tanto à direita como à esquerda, distribuem-se na parte lombar (pilar lateral e medial) do lado correspondente, fornecendo ainda o ramo dorsal direito para o folíolo dorsal direito, um filete nervoso $(20,0 \%)$, dois filetes $(2,0 \%)$, e para o centro tendíneo um filete nervoso $(2,0 \%)$, cedendo ainda o ramo dorsal esquerdo em todos os casos, um filete nervoso para o pilar medial direito, um filete nervoso para o foliolo dorsal esquerdo $(6,0 \%)$ c um filete nervoso para o centro tendíneo $(6,0 \%)$; os ramos laterais dos nervos frênicos $\mathrm{cm}$ todos os casos, tanto à direita como à esquerda, distribuem-se na parte costal, mas exatamente na região laterodorsal do lado correspondente, fornecendo, ainda, um filete nervoso ao foliolo dorsal direito $(12,0 \%)$, dois filetes $(2,0 \%)$ e um filete nervoso para a parte lombar direita, mas exatamente para o pilar direito $(4,0 \%)$, cedendo o ramo lateral esquerdo para o folíolo dorsal esquerdo um filete nervoso $(16,0 \%)$ e dois filetes nervosos $(4,0 \%) ; 3)$ Os ramos ventrais dos nervos frênicos $(100,0 \%)$ dos casos, tanto à direita como à esquerda, distribuem-se às regiões lateroventral da parte costal e esternal do lado correspondente, fornecendo, ainda, o ramo ventral direito para o centro tendíneo um filete nervoso $(6,0 \%)$, um filete nervoso à veia cava caudal $(4,0 \%)$ e um filete nervoso para o folíolo ventral direito $(2,0 \%) ; 4)$ Conexões homolaterais aparecem $(20,0 \%)$, isto é, à direita $(12,0 \%)$ e à esquerda $(4,0 \%)$ e conexōes heterolaterais surgem apenas em $2,0 \%$, entre os ramos dorsais direito e esquerdo.

\section{MATERIAL E MÉTODO}

Para o estudo a que nos propusemos, trabalhamos com 30 diafragmas de jumentos do Nordeste brasileiro (Asinus asinus. Gray, 1824, ex. Fritsch, 1775) ${ }^{15}$, sendo 15 de machos e 15 de fêmeas, adultos, procedentes de diversas regiões do Nordeste brasileiro e abatidos no Matadouro e Frigorífico Industrial S.A. (MAFISA), localizado no município de Belo Jardim, PE. Após a evisceração da cavidade abdominal, procedemos à retirada do diafragma, seccionado junto às suas inserçōes lombar, costal e esternal, tendo o cuidado de, uma vez identificados os nervos frênicos, preservá-los em segmentos de aproximadamente l() $\mathrm{cm}$, ainda quando indivisos. Depois de lavados $\mathrm{cm}$ água corrente, os diafragmas foram distendidos e fixados sobre prancha rígida e, assim, imersos em solução aquosa de formol a $10 \%$. Posteriormente, efetuamos a dissecação de interesse, com o auxílio de lupa Nikon (10x), abordando o músculo por face torácica e registrando em esquemas (Fig. 1, 2) os arranjos encontrados relativos ao comportamento dos nervos frênicos quanto à sua ramificação e distribuição no diafragma. Para a descrição dos resultados (Fig. 1), adotamos da Nomina Anatomica Veterinaria ${ }^{16}$ as expressões pars lumbalis, pars costalis e pars sternalis para designar segmentos da porção carnosa do diafragma cuja inserção se faz, por ordem, nos pilares, nas costelas com suas respectivas cartilagens e na cartilagem xifóidea do esterno. Em face do exposto, decidimos 
designar os ramos terminais dos nervos frênicos que atingem os aludidos segmentos da porção carnosa de ramos lombar, costal e esternal, respectivamente, e aos seus eventuais troncos de origem, de tronco lombocostal e tronco costoesternal.

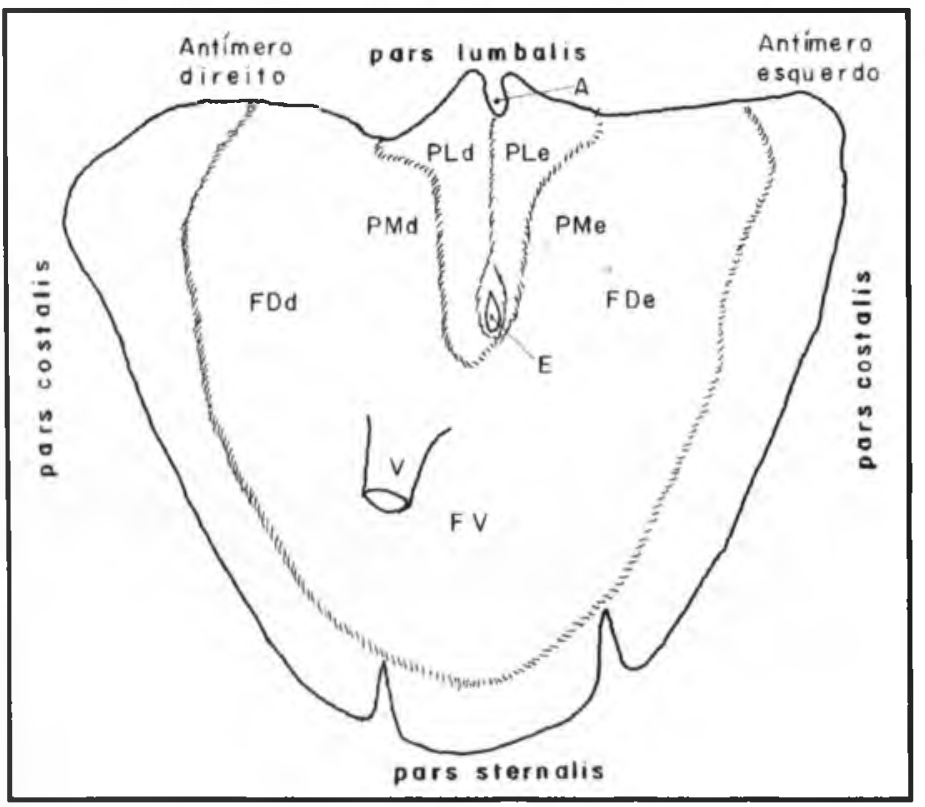

Figura 1

Esquema representativo de diafragma (face torácica) de jumento Nordestino.

\footnotetext{
PLd - pilar lateral direito

PLe - pilar lateral esquedo

PMa - pllar medial direito

PMe - pllar medial esquerdo

FDd - folíolo dorsal direito

FDe - tolíolo dorsal esquerdo

$F V$ - folíolo ventral

A - hiato aórtico

E - hiato esofágico

$V$ - veia cava caudal
}

Relativamente à pars lumbalis, adotamos a divisão efetuada por Schmaltz ${ }^{24}$ (1928), que considera quatro pilares, ou seja, um lateral direito, um medial direito, um medial esquerdo e um lateral esquerdo, os três primeiros originando-se de um tendão comum colocado à direita e o último de outro tendão colocado à esquerda. O comportamento dos ramos destinados à pars costalis determina a ocorrência de duas regiōes com dimensões variáveis denominada dorsal (relacionada ao folíolo dorsal) e a outra, ventral (relacionada ao folíolo ventral); a primeira região corresponde ao território de distribuição dos ramos costais propriamente ditos, do tronco lombocostal ou diretamente do nervo frênico; já a segunda região, ao território inervado por ramos costais dependentes do ramo esternal.

De outra parte, com vistas à eleição de critério para o estabelecimento de limite entre os antímeros do diafragma, observamos que a pars sternalis encontra-se delimitada, em correspondência à linha mediana, por expansāo do ligamento falciforme, disso resultando sua natural divisão. A extensão desta linha coincide dorsalmente com a direção da rafe da pars lumbalis disposta entre os pilares mediais direito e esquerdo.

A análise estatística dos resultados foi conduzida com baso na aplicaçāo do teste de $X^{2}$ (Marascuillo) e do teste da diferença entre duas proporções com aproximação normal.

\section{RESULTADOS}

Para a descrição dos resultados, observamos a ramificação c a distribuiçāo dos nervos frênicos no diafragma (Fig. 2).

\section{1) Ramos terminais do nervo frênico direito}

a) Em 23 diafragmas $(26,7 \% \pm 7,7)$, pertencentes a 12 fêmeas e 11 machos (Fig. 2 - 2f, 3f, $4 \mathrm{~m}, 5 \mathrm{~m}$, 6f, $7 \mathrm{~m}$, $8 \mathrm{~m}, 9 \mathrm{f}, 10 \mathrm{f}, 11 \mathrm{f}, 12 \mathrm{~m}, 13 \mathrm{~m}, 14 \mathrm{~m}, 15 \mathrm{~m}, 16 \mathrm{f}, 17 \mathrm{f}, 22 \mathrm{~m}$, $23 \mathrm{~m}, 24 \mathrm{f}, 25 \mathrm{~m}, 26 \mathrm{f}, 27 \mathrm{f}$ e $28 \mathrm{f}$ ), observamos o nervo frênico resolvendo-se em tronco lombocostal e ramo esternal;

b) Em 4 casos $(13,3 \% \pm 6,2)$, sendo de 2 fêmeas e de 2 machos (Fig. 2 - 1m, 18f, 19f e 30m), verificamos o nervo frênico emitindo os ramos lombar, costal c esternal simultaneamente;

c) Em duas peças $(6,7 \% \pm 4,6)$, pertinentes a 1 macho e 1 fêmea (Fig. 2 - 20m e 29f), notamos o nervo frênico dividindo-se em tronco lombocostal e ramo esternal, afora ramo para pars costalis;

d) Em 1 dissecação $(3,3 \% \pm 3,3)$, em 1 macho (Fig. 2 $21 \mathrm{~m}$ ), deparamos o nervo frênico emitindo tronco lombocostal e ramo esternal, além de pequeno ramo para o folíolo ventral.

\section{2) Ramos terminais do nervo frênico esquerdo}

a) Em 16 preparações $(53,3 \%+9,1)$ de 7 machos e 9 fêmeas (Fig. 2 - 2f, 3f, 4m, 5m, 12m, 14m, 16f, 17f, 18f, $19 \mathrm{f}, 23 \mathrm{~m}, 24 \mathrm{f}, 26 \mathrm{f}, 27 \mathrm{f}$ e $3(0 \mathrm{~m})$, registramos o nervo frênico fornecendo tronco lombocostal e ramo esternal;

b) Em 7 diafragmas $(23,3 \% \pm 7,7)$ de 4 machos e 3 fêmeas (Fig. 2 - 8m, 9f, $13 \mathrm{~m}, 15 \mathrm{~m}, 28 \mathrm{f}$ e $29 \mathrm{f}$ ), verificamos o nervo frênico emitindo um ramo lombar, um ramo costal e um ramo esternal simultaneamente;

c) Em 5 peças $(16,7 \% \pm 6,8)$, atinentes a 3 machos c 2 fêmeas (Fig. 2 - 1m, 10f, 20m e $21 \mathrm{~m}$ ), identificamos o nervo frênico emitindo ramo lombar e tronco costoesternal;

d) $\operatorname{Em~} 1$ caso $(3,3 \% \pm 3,3)$, macho (Fig. 2 - 22m), observamos o nervo frênico cedendo ao mesmo tempo ramo lombar, tronco lombocostal e ramo esternal;

e) Em 1 dissccação $(3,3 \% \pm 3,3)$, fêmea (Fig. 2 - 6f), surpreendemos o nervo frênico emitindo um ramo lombar, um tronco lombocostal, um esternal e um ramo costal ao mesmo tempo.

3) Ramos terminais dos nervos frênicos direito e esquerdo considerados em conjunto 
AMORIM IÚNIOR, A.A.; PRADA, I.L.S.; MIGLINO, M.A. Ramificação e distribuição dos nervos frênicos no dialragma de jumentos do Nordesile brasileiro. Braz. J. vet. Res. anim. Sci. Sāo Paulo, v.33, supl., p.261-269, 1996

a) Em 13 preparaçōes $(43,3 \%+9,0)$, sendo 7 fêmeas e 6 machos (Fig. 2 - 2f, 3f, 4m, $5 \mathrm{~m}, 7 \mathrm{~m}, 12 \mathrm{~m}, 14 \mathrm{~m}, 16 \mathrm{f}$, $17 f, 23 \mathrm{~m}, 24 \mathrm{f}, 26 \mathrm{f}$ e 27f), verificamos os nervos frênicos direito e esquerdo fornecendo tronco lombocostal e ramo esternal;

b) Em 6 peças $(20,0 \% \pm 7,3)$ de 4 machos e 2 fêmeas (Fig. 2 - $8 \mathrm{~m}, 9 \mathrm{f}, 13 \mathrm{~m}, 15 \mathrm{~m}, 25 \mathrm{~m}$ e $28 \mathrm{f}$ ), notamos o nervo frênico à dircita, fornecendo tronco e ramo esternal, e à esquerda a modalidade de trifurcação;

c) Em 3 peças $(3,3 \% \pm 3,3)$, macho (Fig. 2 - 22m), deparamos o nervo frênico direito fornecendo os ramos lombar, costal e esternal concomitantemente, e o esquerdo, o tronco lombocostal e esternal;

d) Em dois casos $(6,7 \% \pm 4,6)$, pertencentes a 2 fêmeas (Fig. 2 - 10f e l lf), verificamos o nervo frênico à direita dividindo-se em tronco lombocostal e ramo esternal, já à esquerda, em ramo lombar e tronco costoesternal;

e) $\operatorname{Em} 1$ dissecação $(3,3 \%+3,3)$, macho (Fig. $2-1 \mathrm{~m}$ ), deparamos, à direita, o nervo frênico emitindo ronco lombocostal, ramo esternal e um ramo para o folíolo ventral, e à esquerda dividindo-se em ramo lombar e tronco costoesternal;

f) $\mathrm{Em} \mathrm{l}$ caso $(3,3 \%+3,3)$, macho (Fig. $2-1 \mathrm{~m}$ ), deparamos o nervo frênico direito originando uma modalidade de trifurcação, enquanto o esquerdo, um ramo lombar e um tronco costoesternal;

g) Em I diafragma $(3,3 \% \pm 3,3)$, macho (Fig. $2-20 \mathrm{~m})$, notamos o nervo frênico direito emitindo um tronco lombocostal, um ramo costal e um esternal, enquanto o esquerdo, um ramo lombar e tronco costoesternal;

h) Em I preparação $(3,3 \% \pm 3,3)$, de fêmea (Fig. 2 - 29f), deparamos o nervo frênico à direita, emitindo tronco tombocostal, ramo costal e ramo esternal, e à esquerda, os ramos lombar, costal e esternal simultaneamente;

i) Em 1 peça $(3,3 \% \pm 3,3)$, de fêmea (Fig. $2-22 \mathrm{~m}$ ), surpreendemos o nervo frênico direito dividindo-se em tronco lombocostal e ramo esternal e o nervo frênico esquerdo, um ramo lombar, um tronco lombocostal e um ramo esternal.

\section{4) Distribuição do ramo lombar do nervo frênico direito}

a) Em 26 diafragmas $(86,7 \% \pm 6,2)$ pertencentes a 13 fêmeas e 13 machos (Fig. 2 - 1m, 2f, 4m, 5m, 6f, 7m, 9f, I0f, 1If, $12 \mathrm{~m}, 13 \mathrm{~m}, 14 \mathrm{~m}, 15 \mathrm{~m}, 16 \mathrm{f}, 18 \mathrm{f}, 19 \mathrm{f}, 20 \mathrm{~m}$, $22 \mathrm{~m}, 23 \mathrm{~m}, 24 \mathrm{f}, 25 \mathrm{~m}, 26 \mathrm{f}, 27 \mathrm{f}, 29 \mathrm{f}$ c $30 \mathrm{~m})$, identificamos o ramo lombar distribuindo-se apenas no antímero direito da pars lumbalis (pilares lateral dircito c medial direito);

b) Em 2 casos $(6,7 \% \pm 4,6)$, sendo 1 macho e 1 fêmea (Fig. 2 - 3f e $8 \mathrm{~m}$ ), presenciamos o ramo lombar emitindo ramos aos pilares lateral direito e medial direito e filete nervoso ao folíolo dorsal direito do diafragma;

c) Emı l peça $(3,3 \% \pm 3,3)$, fêmea (Fig. 2 - 17f), surpreendemos o ramo lombar alcançando os pilares lateral direito e medial direito, bem como o pilar medial esquerdo do diafragma;

d) Em I animal $(3,3 \% \pm 3,3)$, macho (Fig. 2 - $21 \mathrm{~m}$ ), deparamos o ramo lombar dirigindo-se aos pilares lateral direito e medial direito, bem como ao folíolo ventral.

\section{5) Distribuição do ramo lombar do nervo frênico esquerdo}

a) Em 13 preparações $(43,3 \% \pm 9,0)$, sendo 5 fêmeas e 8 machos (Fig. 2 - 2f, $5 \mathrm{~m}, 10 \mathrm{f}, 12 \mathrm{~m}, 15 \mathrm{~m}, 16 \mathrm{f}, 20 \mathrm{~m}, 21 \mathrm{~m}$, $23 \mathrm{~m}, 24 \mathrm{f}, 25 \mathrm{~m}, 28 \mathrm{f} \mathrm{e} 3() \mathrm{m})$, verificamos o ramo lombar destinando-se apenas aos pilares lateral esquerdo e medial esquerdo e pilar medial direito da pars lumbalis;

b) Em 11 dissecações $(36,7 \% \pm 8,8)$, sendo de 7 fêmeas e 4 machos (Fig. 2 - 1m, 6f, 7m, 9f, 11f, 14m, 17f, 18f, $22 \mathrm{~m}$, $26 \mathrm{f}$ e 29f), notamos o ramo lombar alcançando somente os pilares lateral esquerdo e medial esquerdo da pars lumbalis. Esclareça-se que, na Fig. 2 (6f e $22 \mathrm{~m}$ ), observamos a presença de 2 ramos lombares;

c) Em 2 peças $(6,7 \% \pm 4,6)$, de 1 macho e 1 fêmea (Fig. 2 - $13 \mathrm{~m}$ e 19f), surpreendemos o ramo lombar atingindo os pilares esquerdo e medial esquerdo da pars lumbalis c emitindo filete nervoso para o folíolo dorsal esquerdo;

d) Em 2 casos $(6,7 \% \pm 4,6)$, de 1 macho e 1 fêmea (Fig. 2 $13 \mathrm{~m}$ e $19 \mathrm{f}$ ), surpreendemos o ramo lombar alcançando o antímero esquerdo da pars lumbalis, e o pilar medial direito do diafragma, além de emitir filete nervoso ao folíolo dorsal esquerdo;

e) Em 1 animal $(3,3 \% \pm 3,3)$, de fêmea (Fig. 2 - 4f), surpreendemos o ramo lombar alcançando o antímero esquerdo da pars lumbalis e emitindo filete nervoso que se bifurca no folíolo ventral.

Enquanto a distribuição do ramo lombar direito mostrou-se tipicamente homolateral (à exceção de um calso), o ramo lombar esquerdo surge em mais da metade das peças $(5,3,3 \%)$, emitindo filetes para o antímero oposto, melhor especificando, para o pilar medial direito. Este comportamento do ramo lombar esquerdo, aliás, representa a única modalidade de distribuição contralateral dos próprios nervos frênicos, uma vez que os ramos costais e esternais, tanto à direita como à esquerda, não ultrapassam o plano sagital mediano.

\section{6) Distribuição do ramo costal do nervo frênico direito}

a) Em 19 preparaçōes $(96,7 \%+3,3)$, sendo de 14 fêmeas c 15 machos (Fig. 2 - Im, 2f, 4m, 5m, 6f, 7m, 8m, 9f, 10f, $11 \mathrm{f}, 12 \mathrm{~m}, 13 \mathrm{~m}, 14 \mathrm{~m}, 15 \mathrm{~m}, 16 \mathrm{f}, 17 \mathrm{f}, 18 \mathrm{f}, 19 \mathrm{f}, 20 \mathrm{~m}, 21 \mathrm{~m}$ $22 \mathrm{~m}, 23 \mathrm{~m}, 24 \mathrm{f}, 25 \mathrm{~m}, 26 \mathrm{f}, 27 \mathrm{f}, 28 \mathrm{f}, 29 \mathrm{f}$ e $30 \mathrm{~m})$, registramos o ramo costal alcançando somente a região dorsal da pars costalis do diafragma;

b) Em I animal $(3,3 \% \pm 3,3)$, de fêmcas (Fig. 2 - 2f), surpreendemos o ramo costal destinando-se à região dórsal da pars costalis e emitindo também filete nervoso ao folíolo dorsal direito. 
AMORIM JUNIOR, A.A.; PRADA, I.L.S.; MIGLINO, M.A. Ramificaçāo e distribuiçâo dos nervos frênicos no diafragma de jumentos do Nordeste brasileiro. Braz. .J. vet. Res. aninı. Sci. São Paulo, v.33, supl., p.261-269, 1996.

\section{7) Distribuição do ramo costal do nervo frênico esquerdo}

a) Em 24 diafragmas $(80,0 \% \pm 7,3)$, de 9 fêmeas e 15 machos (Fig. 2 - 1m, 4m, 5m, 6f, 7m, 8m, 9f, lof, $11 \mathrm{f}$, $12 \mathrm{~m}, 13 \mathrm{~m}, 14 \mathrm{~m}, 15 \mathrm{~m}, 17 \mathrm{f}, 18 \mathrm{f}, 19 \mathrm{f}, 21 \mathrm{~m}, 22 \mathrm{~m}, 23 \mathrm{~m}$, $25 \mathrm{~m}, 26 \mathrm{f}, 27 \mathrm{f}$ e $30 \mathrm{~m}$ ), identificamos o ramo costal distribuindo-se apenas à região dorsal da pars costalis. Note-se, na Fig. 2 - of, a presença de mais um ramo costal. menor, oriundo diretamente do nervo frênico, tendo o mesmo destino do anterior;

b) Em 6 peças $(20,0 \% \pm 7,3)$, todos de fêmeas (Fig. 2 - 2f, 3f, 16f, 24f, 28f e 29f), deparamos o ramo costal distribuindo-se à região dorsal da pars costalis e emitindo ainda filete nervoso ao folíolo dorsal esquerdo.

\section{8) Distribuição do ramo esternal do nervo frênico direito}

a) Em apenas 1 peça $(3,3 \%+3,3)$, de macho (Fig. $2-4 \mathrm{~m})$, surpreendemos o ramo esternal indo à pars sternalis (antímero direito) e à região ventral da pars costalis, além de emitir filcte para a veia cava caudal; e nos demais casos o ramo esternal se destinava somente à pars sternalis (antímero direito) e à região ventral da pars costalis do diafragma.

\section{9) Distribuição do ramo esternal do nervo frênico esquerdo}

Em todas as preparaçōes deparamos o ramo esternal esquerdo distribuindo-se na pars stemalis (antímero esquerdo) e na regiāo ventral da pars costalis do diafragma.

10) Conexões homo e heterolaterais entre os ramos terminais dos nervos frênicos direito e esquerdo

a) Em 8 peças $(26,7 \% \pm 8,1)$, sendo 5 de machos e 2 de fêmeas (Fig. 2 - 2f, 15m, 17m, 18m, 21m, 22m, 27f e 29f), verificamos uma conexāo entre filetes nervosos dos ramos lombares direito e esquerdo;

b) Em 3 dissecações $(10,0 \% \pm 5,5)$, sendo 2 de fêmeas e 1 de macho (Fig. 2 - 6f, $17 \mathrm{f}$ e $21 \mathrm{~m}$ ), surpreendemos conexão relativamente ao próprio ramo lombar esquerdo; note-se que, na Fig. 2 - 6f, a citada conexão relaciona entre si dois ramos lombares esquerdos;

c) Em 1 animal $(3,3 \% \pm 3,3)$, macho (Fig. 2 - 5m), deparamos conexão entre os ramos lombar esquerdo e costal esquerdo; ainda em I peça $(3,3 \% \pm 3,3)$, de macho (Fig. $2-15 \mathrm{~m}$ ), notamos uma conexão entre os ramos lombar direito e costal direito; também foi evidenciada uma conexão entre filetes nervosos do ramo lombar direito e I caso $(3,3 \% \pm 3,3)$, de fêmea (Fig. 2 $27 \mathrm{f}$ ), bem como entre filetes nervosos do ramo costal direito e 1 peça $(3,3 \% \pm 3,3)$, de fêmea (Fig. 2 - 10f).

Conforme relatamos, as conexões heterolaterais dos nervos frênicos direito e esquerdo ficam sempre por conta de seus ramos lombares, já que correspondentes ramos costais participam apenas de conexóes homolaterais, e os esternais, nem das primeiras nem das últimas.

\section{Figura 2}

Esquemas (correspondentes às Obs. de 1-30) representativos da ramificação e distribuição dos nervos frênicos direito e esquerdo no diafragma (face torácica) de jumentos Nordestinos.
1 - nevo frênico direito
2 - nervo frênico esquerdo
3 - tronco lombocostal direito
4 - tronco lombocostal esquerdo
5 - tronco costoesternal direito
6 - ramo lombar direito
7 - ramo lombar esquerdo
8 - ramo costal direito
9 - ramo costal esquerdo
10 - ramo esternal direito
11 - ramo esternal esquerdo
a - conexão entre filetes nervosos

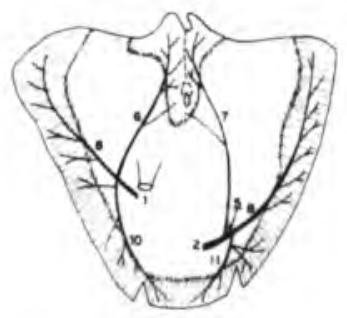

Fig. $1 \mathrm{~m}$

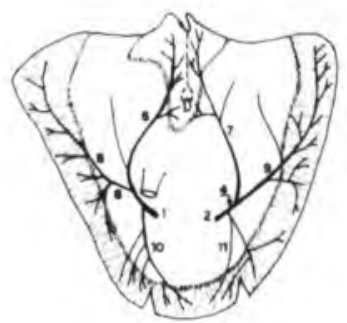

Fig. $3 f$

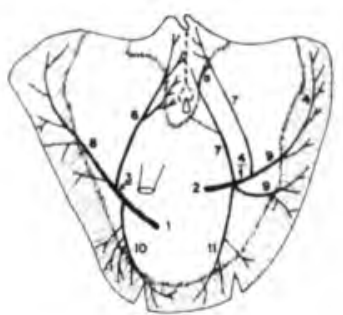

Fig. $5 m$

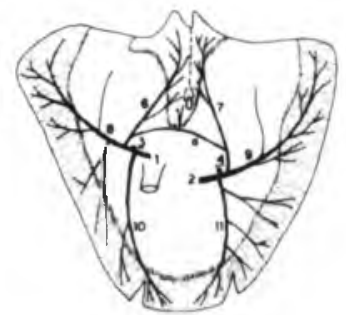

Fig. $2 f$

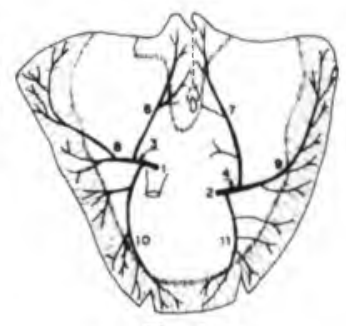

Fig. $4 \mathrm{~m}$

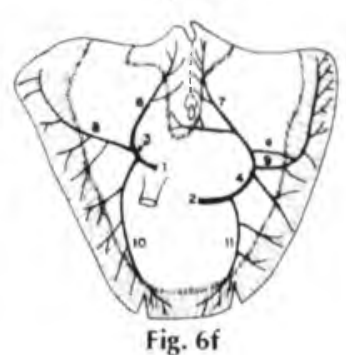

Fig. $6 f$ 
AMORIM JÚNIOR, A.A.; PRADA, I.L.S.; MIGLINO, M.A. Ramificaçăo e distribuiçāo dos nervos frênicos no diafragma de jumentos do Nordeste brasileiro. Braz. J. vet. Res. anim. Sci. Săo Paulo, v.33, supl., p.261-269, 1996.

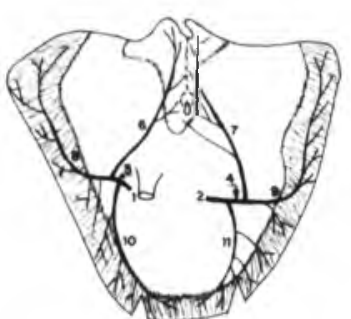

Fig. $7 \mathbf{m}$

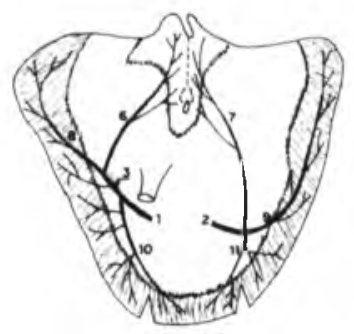

Fig. $9 f$

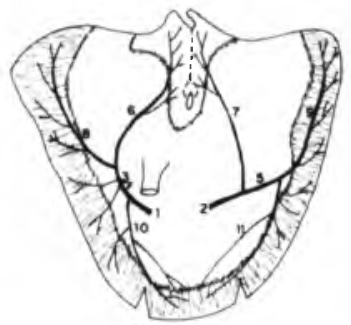

Fig. 11f
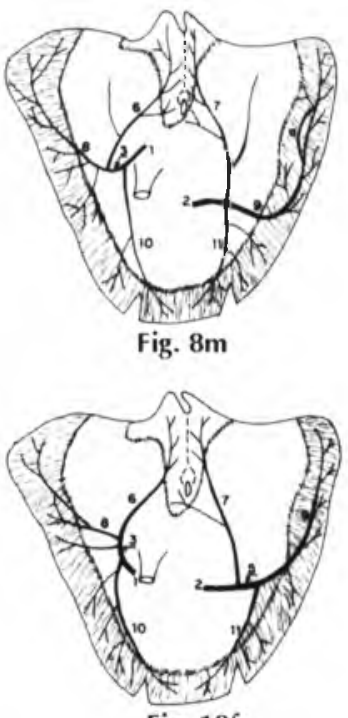

Fig. $10 \mathrm{f}$

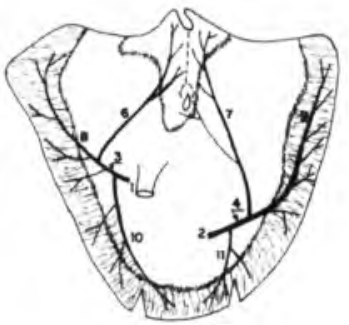

Fig. $12 \mathrm{~m}$

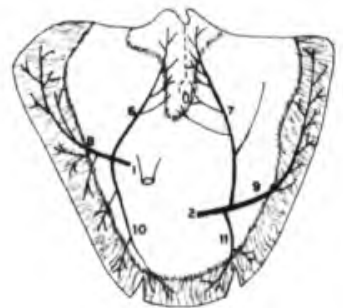

Fig. $19 f$

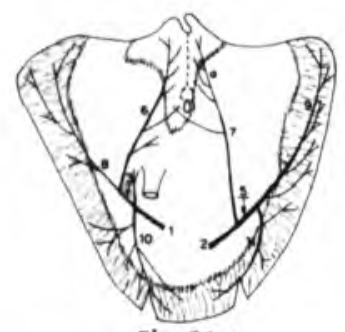

Fig. $21 \mathrm{~m}$

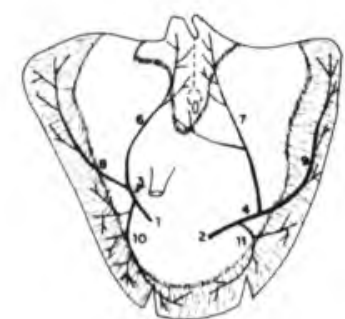

Fig. $23 \mathrm{~m}$

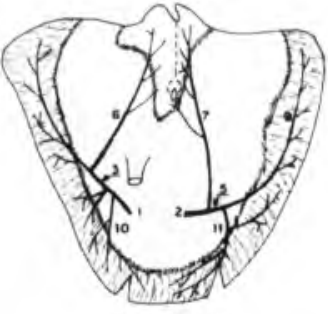

Fig. $20 \mathrm{~m}$

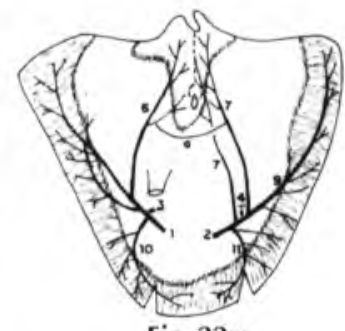

Fig. $22 \mathrm{~m}$

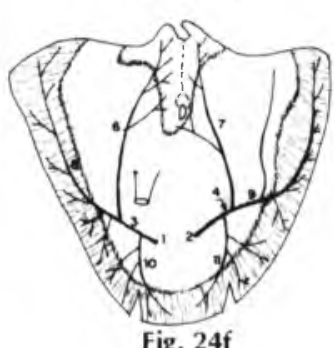

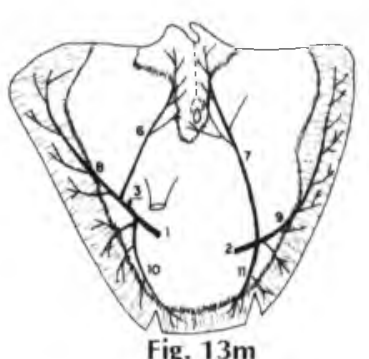
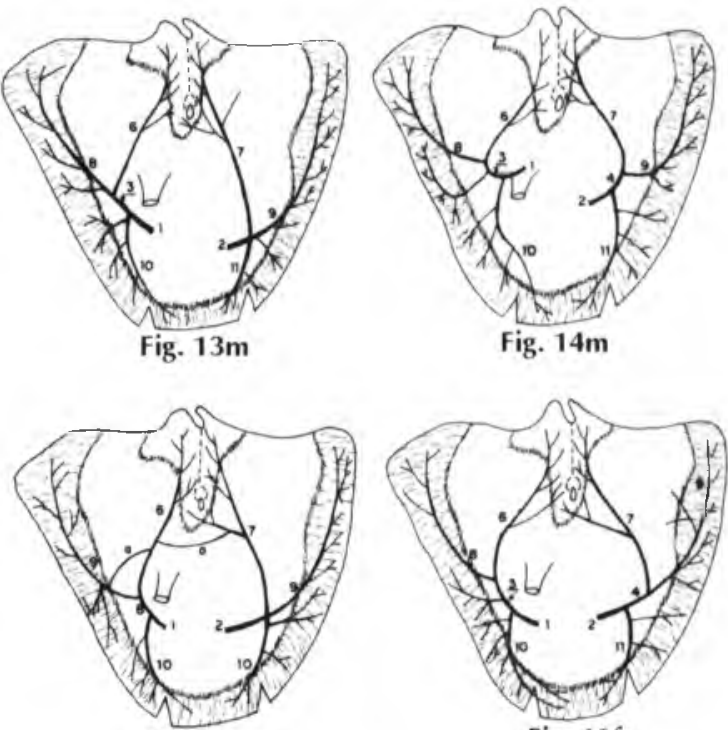

Fig. $15 \mathrm{~m}$

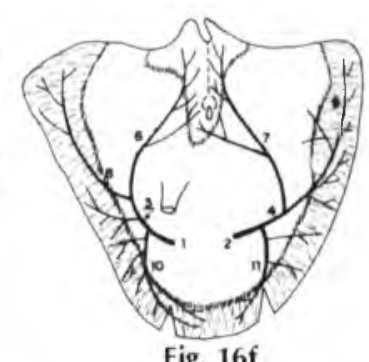

Fig. $16 f$

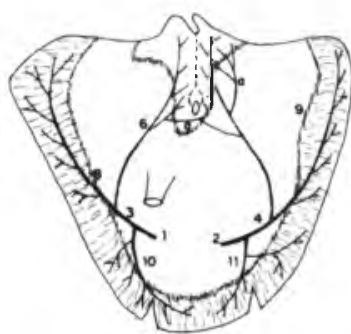

Fig. $17 f$

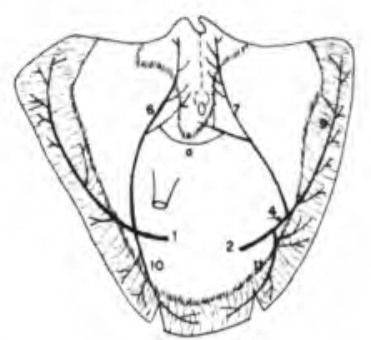

Fig. $18 \mathrm{f}$

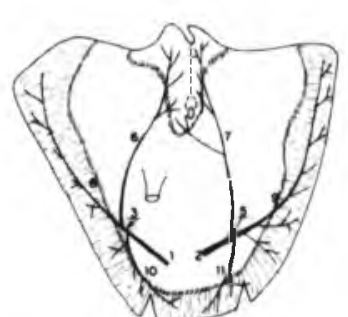

Fig. $25 \mathrm{~m}$

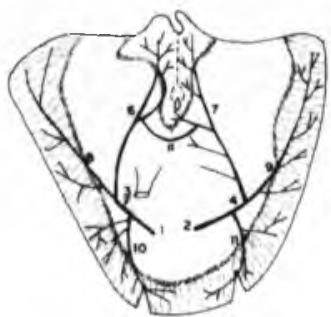

Fig. $27 f$

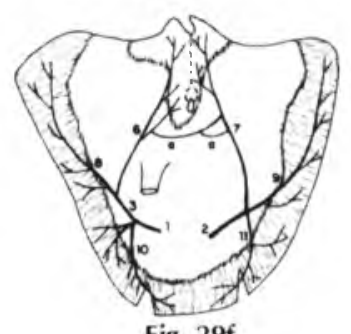

Fig. $29 f$

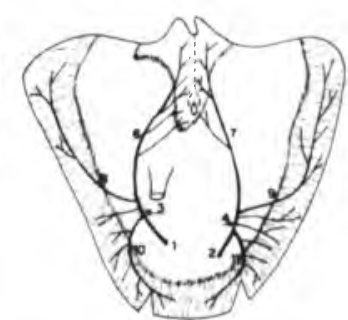

Fig. $26 f$

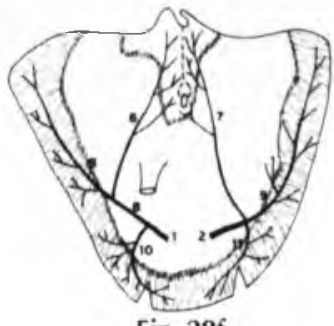

Fig. $28 f$

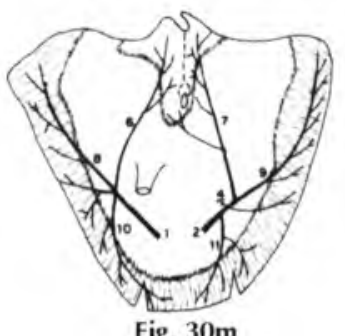


AMORIM JÚNIOR, A.A.; PRADA. I.L.S.; MIGLINO, M.A. Ramificaçāo e distribuição dos nervos frênicos no diafragma de jumentos do Nordeste brasileiro. Braz. J. vet. Res. anim. Sci. São Paulo, v.33, supl., p.261-269, 1996.

\section{DISCUSSÃO E CONCLUSÕES}

Ao revermos as descriçōes contidas nos tratados de Anatomia Veterinária, no que concerne à divisão terminal dos nervos frênicos nos eqüídeos, observamos que Bossi et al. ${ }^{4}$ (s.d.); Lesbre ${ }^{17}$ (1923); Zimmerl ${ }^{27}$ (1930); Ellenberger; Baum ${ }^{11}$ (1932); Bruni; Zimmerl ${ }^{5}$ (1947); Gonzalez y Garcia; Gonzalez Alvarez $^{14}$ (1949); indicam que os aludidos nervos ao chegarem no centro frênico do diafragma dividem-se e subdividem-se em filetes nervosos para alcançarem a porção carnosa, referência esta similar às exaradas, neste sentido, por Sisson; Grosmann ${ }^{26}$ (1948); Dobberstein; Hoffmann ${ }^{10}$ (1964); Schwarze; Schröder ${ }^{25}$ (1972) e Getty ${ }^{13}$ (1975). Entretanto, assim como Santiago; Pereira $^{22}$ (1983), eqüinos da raça Puro Sangue Inglês, e Santiago $^{23}$ (1986), para eqüinos Sem Raça Definida, encontramos, para os jumentos Nordestinos, os nervos frênicos alcançando não apenas a porção carnosa, mas também os foliolos dorsal e ventral e a parede da veia caudal. A inervação dessas estruturas, pelos nervos frênicos leva-nos à reflexão ante a afirmativa de Dobberstein e Hoffmann ${ }^{10}$ (1964) e Getty ${ }^{13}$ (1975) de que eles constituem a inervação motora do diafragma, pois sabemos que o nervo frênico, como todo nervo misto, possui, além de fibras motoras, também fibras sensitivas.

No atinente aos ramos terminais dos nervos frênicos, observamos a presença constante de três ramos principais, de cada lado, tal como descreve Pancrazi ${ }^{21}$ (1926), para o cavalo e outras espécies.

Consultando a literatura especializada, vale salientar que encontramos as denominações de ramos dorsal, lateral e ventral para os principais ramos terminais dos nervos frênicos. Preferimos, considerando a natural disposição desses ramos terminais nos diferentes segmentos da porçāo carnosa (pars lumbalis, pars costalis e pars sternalis), designá-los, respectivamente, lombar, costal e esternal. Os três ramos citados podem nascer do nervo frênico homolateral por trifurcação ou bifurcação, nesse caso com a formação de um tronco lombocostal e costoesternal. Em nosso trabalho, mais freqüentemente registramos a modalidade de bifurcação à direita $(86,7 \%)$, com a presença de tronco lombocostal e ramo esternal, o mesmo achado tendo sido descrito para os eqüinos PSI - Puro Sangue Inglês $(96,7 \%)$ e SRD - Sem Raça Definida $(84,0 \%)$. Quanto à possibilidade de trifurcação, verificou-se a similaridade entre os jumentos Nordestinos $(13,3 \%)$ com os eqüinos SRD $(12,0 \%)$, o que não foi observado nos eqüinos PSI Considerando a mesmo tempo os nervos frênicos direito e esquerdo, no atinente à modalidade de trifurcação, deparamos significância no nível de rejeição de $5 \%$ quando comparamos os nossos dados com os de animais PSl, o mesmo não acontecendo no tocante aos SRD Quanto à modalidade de bifurcação com presença de tronco costoesternal, não evidenciamos na presente pesquisa, sendo raramente observada tanto no PSI $(3,3 \%)$ quanto no SRD $(4,0 \%)$. O comportamento descrito, do nervo frênico direito, em eqüinos PSI, SRD e jumentos Nordestinos dispensa qualquer elaboração estatística, dada a freqüência majoritária, nos três grupos de animais, da ocorrência de bifurcação com presença de tronco lombocostal.

Quanto ao antímero esquerdo, no jumento Nordestino também mais freqüentemente $(53,3 \%)$ que as outras possibilidades de divisão, mas menos freqüentemente que o observado à direita $(86,7 \%)$, o nervo frênico divide-se por bifurcação em tronco lombocostal e ramo esternal, o mesmo não acontecendo com o PSI $(26,7 \%)$ e com o SRD $(10,0 \%)$, nos quais o arranjo mais freqüente é o de bifurcaçāo em tronco costoesternal e ramo lombar: PSI - 66,7\% c SRD - 80,0\%, diferentemente do registrado para o jumento Nordestino $(16,7 \%)$. Diante destas marcantes diferenças, procedemos à análise estatística dos dados, levando em consideração, simultaneamente, os nervos frênicos direito e esquerdo. Assim, confrontando os nossos resultados com os de animais PSI, não se registrou diferença estatisticamente significante, o mesmo nāo acontecendo em relação aos de eqüinos SRD, quando a análise estatística conduzida com base no teste de diferença entre duas proporçôes com aproximação normal igual a 2,21 mostrou significância no nível de rejeiçāo de 5,0\%; isto significa que o número de vezes em que, proporcionalmente, os nervos frênicos direito e esquerdo emitiram tronco lombocostal e ramo esternal foi significantemente maior em jumentos do que em SRD Quanto à outra modalidade de bifurcação, ou seja, em tronco costoesternal e ramo lombar, analisando as terminações dos nervos frênicos em ambos os lados, notamos que são semelhantes os dados relativos aos animais SRD $(42,0 \%)$ e PSI $(35,0 \%)$, diferindo deles, entretanto, os atinentes aos jumentos $(8,3 \%)$. Do que acabamos de expor, notamos que para cada modalidade de ramificação dos nervos frênicos há uma relação diferente entre os três grupos de eqüídeos confrontados, isto é, com vista à bifurcação por tronco lombocostal e ramo esternal, o jumento e o PSI apresentam distribuiçāo semelhante quantitativamente, diferindo com significância dos animais SRD, o mesmo não acontecendo com a modalidade de trifurcação para a qual jumentos e SRD diferenciam-se estatisticamente dos PSI; já com relação do tipo de bifurcação por tronco costoesternal e ramo lombar, notamos uma predominância de ocorrência desta modalidade nos animais SRD e PSI, comparativamente ao jumento Nordestino.

Analisando agora os ramos terminais dos nervos frênicos considerados em conjunto, quanto às possibilidades de arranjos simétricos, encontramos com maior freqüência nos animais PSI $(26,7 \%)$, SRD $(10,0 \%)$ e jumentos $(43,3 \%)$ bifurcação por tronco lombocostal e ramo esternal; de outra parte, raramente nos eqüídeos PSI $(3,3 \%)$ e SRD (4,0\%) observamos simetria bilateral no caso de os nervos frênicos emitirem tronco costoesternal e ramo lombar, ocorrência nāo registrada para os jumentos. Trifurcação simétrica é a modalidade menos freqüente nos três grupos, tendo sido raramente observada, e unicamente nos animais SRD (4,0\%). Com essas variaçōes podemos apenas confirmar a afirmativa de Pancrazi ${ }^{21}$ (1926) de que a divisão dos nervos frênicos varia segundo a espécie e entre representantes da mesma espécie.

Além das regiōes já descritas (porção muscular) das quais

\section{JERVICO DE BIBLIOTECA E DOCUMENTACĀO \\ FACULDAD- DE MEDICINA VETERINARIA E ZOOTECNIA DA USP}


AMORIM JÚNIOR, A.A.; PRADA, I.L.S.; MIGLINO, M.A. Ramificaçăo e distribuição dos nervos frênicos no dialragma de jumentos do Nordeste brasileiro. Braz. J. vet. Res. anim. Sci. São Paulo, v.33, supl., p.261-269, 1996.

são inervadas por ramos correspondentes, isto é, ramos lombar, costal e esternal, encontramos também filetes desses ramos endereçados a outras estruturas, em $56,7 \%$ dos casos, ou seja, folíolo dorsal direito (10,0\%), folíolo dorsal esquerdo $(33,3 \%)$, folíolo ventral $(10,0 \%)$ e veia cava caudal $(3,3 \%)$. A análise estatística destes dados, conduzida com base no teste de $\mathrm{X}^{2}$ (igual a 11,01), revelou significância no nível de rejeição de 5\%; em outras palavras, há uma distribuição diferenciada nas diversas partes do centrum tendineo e na parede da veia cava caudal. Nos nossos trabalhos encontramos $56,7 \%$ de casos relativos à inervação das citadas estruturas, enquanto nos eqüinos PSI $(86,7 \%)$ e SRD $(98,0 \%)$. Portanto, nos jumentos observa-se frequência significantemente menor quando comparada com os PSI e SRD No atinente às conexões entre ramos terminais dos nervos frênicos, ou seja, ramos lombar, costal c esternal, observamos em nosso trabalho que elas são homo e heterolaterais, no primeiro caso apresentando-se freqüência de $10,0 \%$ à direita e de $16,7 \%$ à esquerda; relativamente às heterolaterais $(26,7 \%)$, elas ocorreram apenas com a participação dos ramos lombares e nunca com a dos ramos costais ou esternais. No tocante à ocorrência, no jumento Nordestino, das três modalidades de conexões citadas $(53,3 \%)$, a análise estatística conduzida no teste de $X^{2}$ mostrou não haver diferença significante entre elas, no nível de rejeição de $5 \%$, assim como entre os dados relativos às conexões homolaterais quando confrontadas com as heterolaterais. Também, comparando nossos resultados do número total de conexōes homolaterais $(26,7 \%)$ com os alusivos a PSI $(43,3 \%)$ e SRD (20,0\%), vemos que eles se aproximam dos últimos e diferem significantemente dos primeiros. O mesmo não acontece em relação às conexões heterolaterais cuja freqüência nos jumentos $(26,7 \%)$ é marcadamente superior à encontrada para os PSI $(0,0 \%)$ e SRD $(2,0 \%)$.

\section{SUMMARY}

The results obtained from the study of 30 diaphragms of adult asses (Asinus asinus), extracted from 15 male and 15 female animals from the Brazilian Northeastern region, allowed us to reach the following conclusions:

1) The phrenic nerves more frequently result in a lumbocostal trunk and sternal branch, either right (76.7\%) or left $(53.3 \%)$; symmetric disposition was registered in some pieces $(43.3 \%)$;

2) The lumbar branches are destined to the corresponding crura (pars lumbalis); the right branches give small branches to the medial left crus (3.3\%), to the right dorsal foliole $(6.7 \%)$ and to the left dorsal foliole $(3.3 \%)$, and the left ones also give small branches to the medial right crus $(3.3 \%)$ to the left dorsal foliole $(13.3 \%)$ and to the ventral foliole $(6.7 \%)$;

3) The costal branches are distributed to the dorsal region of the pars costalis of each respective side, either right or left, to the right side of the ventral region $(3.3 \%)$ and to the right dorsal foliole $(3.3 \%)$, and the left one to the left dorsal foliole $(10.0 \%)$;

4) The sternal branches are destined to the pars sternalis and ventral region of the pars costalis at the same side; at the right side, they give small branches to the vena cava caudalis $(3.3 \%)$, or to the ventral foliole $(3.3 \%)$.

\section{UNITERMS: Diaphragm; Phrenic nerves; Donkeys; Anatomy.}

\section{REFERÊNCIAS BIBLIOGRÁFICAS}

I-BERTEL .I.I. O. Distribuizione dei nervi frenici diafragma nei mammiferi. Archivio italiano di anatomia e di embriologia, v. 32, n. I, p. $1101-48,1933$

2-BBER'TELI I. O. Contributo alla anatomia del dialragma nei carnivori. Monitori di zoologia italiana, $v .1$, n.9/10, p.211-5, 1984.

3-BLRTELLI, O. Ricerche sulla morfologia del musculo diafragma nei mammiferi Archivio scientifico di medicina veterinaria. v. 19, n. 4, p. $381-437,1985$.

4-BOSSI, V.; CARADONNA, G.13.: SPAMPANI, G.; VARALDI, L.; ZIMMERI, U. Trattato di anatomia veterinaria. Milano, Francesco Vallardi, v.3, p.228 $9.19(10$.

5-BRUNI, A.C., ZIMMERL, U. Anatomia degli animali domestici. Milano, Francesco Vallardi, v.2, p.540, 1947.

6-CAVAL.IÉ, M. De l'innervation du diafragme: étude anatomique et phisiologique. Toulouse. 133p. Thèse Doctoral, 1898.

7-CHAUVEAU, A.; ARLOING, S.L.; LESBRE, F.X. Traité d'anatomie comparée des animaux domestiques. 5.ed. Paris, J.B. Baillière, y. 1, p.407-9, 1905.
8-CONDE, R. Esludo analómico sobre a distribuicāo dos nervos frênicos no músculo diafragna de C'anis familiaris. Arquivos da Escola Superior de Veterinária da Uajersidade Rural do Estado de Minas (ierais, v. I0, p. 329 $65,1957$.

9-CONDE, R. Estudo anatômico com dados experimentais sobre a distriluicão dos nervos frênicos no músculo diafragma de Sus scrofa domesticus. Bčlo Horizonte, 1957. 84p. Tese (Catedrático) - Escolat Superior de Velerinatia, Universidade Rural do Estado de Minas Gerais.

10-DOBBERSTEIN, J.; HOFFMANN, G. Lehrbuch der vergleichende Anatomie der Haustiere. Lcipzig. S. Hirzel, v.3. p. 165, 1964

1 I-ELLENBERGER, W.; BAUM, H. Handbuch der vergleichenden Anatomie der Haustiere. Berlin, J. Springer, p.9(1), 1932.

12-FUNAOKA, S. Untersuchungen über des peripheren Nervensystems. N. phenieus, von Genpei Morita. Arbeitein Analomischen Institüt K. Univ. Kioto. A. v.1, n. 1/2, p. 1652,1930

1.3-GETTY, R. Sisson and Grossman's the anatomy of the domestic animals. 5 ed. Philadelphia, W.B. Saunders, v. 1, p.666-8, 1975.

14-GONZALEZ y GARCIA, J.; GONZALLZ ALVAREZ, R. Anatomia comparada de los animales domésticos. 6. ed. Madrid, Canales, p.803, 1949 
AMORIM JÚNIOR, A.A.; PRADA, I.L.S.; MIGLINO, M.A. Ramificação e distribuição dos nervos frênicos no diafragma de jumentos do Nordeste brasileiro. Braz. J. vet. Res. anim. Sci. São Paulo, v.33, supl., p.261-269, 1996.

15-GRASSÉ, P.P. Traité de Zoologie: anatomie, systematique, biologie. Paris, Maisson, v.17, p. 1066-78, 1955.

16-[NTERNATIONAL COMMITTEE ON VETERINARY GROSS

ANATOMICAL NOMENCLATURE. Nomina Anatomica Veterinaria. 3.

ed., Ithaca, ICVGAN, 209p, 1983

17-LESBRE, F.X. Précis d'anatomie comparée des animaux domestiques. Paris, J.B. Ballière, v.2, p.668-9, 1923

18-LUTNICK, W. The phrenic nerves in the sheep. Annales Universitatis Mariae Curie-Sklodowska v.5, n.4, p.47-69, 1950.

19-LUTNICK, W. The phrenic nerves in diaphragm of pig. Annales Universitatis Mariae Curie-Sklodowska, v.8, p.259-84, 1953.

20-NEVES, I P. Estudo anatômico da distribuição dos nervos frênicos no músculo diafragma de bovinos (fetos). Veterinária, Rio de Janeiro, v.21, n.1, p. $30-45,1968$.

21-PANCRAZI, G. Sulla distribuzione del nervo frenico nel diafragma dei mammiferi (Nota preventiva). Atti del Istituto Veneto di Scienze, Lettere ed Arti. v.85, 1926. apud CONDE, R. Estudo anatômico, com dados experimentais sobre a distribuição dos nervos frênicos no músculo diafragma de Sus scrofa domesticus. Arquivos da Escola Superior de Veterinária da Universidade Rural do Estado de Minas Gerais, v.12, p.37-110, p.41, 83-95, 1959.

22-SANTIAGO, W.: PEREIRA, J.G.L. Contribuição ao estudo da inervação do diafragma em eqüinos da raça Puro Sangue Inglês. Revista da Faculdade de Medicina Veterinária e Zootecnia da USP, v.20, n.2, p.143-53, 1983.

23-SANTIAGO, W. Ramificaçāo e distribuição dos nervos frênicos em diafragma de eqüinos Sem Raça Definida. São Paulo, 1986. 87p. Tese (Doutorado) - Instituto de Ciências Biomédicas, Universidade de Sāo Paulo.

24-SCHMALTZ, R. Anatomie des Pferdes. Berlin, Von Richard Schoetz, p.123-4, 1928.

25-SCHWARZE, R.; SCHRÖDER, L. Compendio de anatomia veterinaria. Zaragoza, Acribia, p.65, 1972.

26-SISSON, S.; GROSSMAN, J.D. The anatomy of domestic animals. 3. ed Philadelphia, W.B. Saunders, p.287-9, 1948.

27-ZIMMERL, U. Apparechio nervoso. In: ZIMMERL, U.; BRUNI, A.C.; CARADONNA, G.B.; MANNU, A.; PREZIUSO, L. Trattato di anatomia veterinaria. Milano, Francesco Vallardi, v.3, p.476, 1930. 